\title{
UNIDAD DE ACCIÓN, UNIDAD DE HECHO Y UNIDAD DE DELITO EN EL CONCURSO DE DELITOS
}

\section{UNIT OF ACTION, UNIT OF FACT AND UNIT OF CRIME IN THE CONCURRENT OFFENSES}

\author{
Francisco Maldonado Fuentes*
}

\begin{abstract}
RESUMEN: La doctrina tradicional sistematiza los concursos de delitos a partir de la distinción entre unidad y pluralidad de hechos, asumida como una diferencia fundamental. Tras ella se sobrevalora la relación entre los casos unitarios y la ejecución de un único delito. El texto explica por qué ese planteamiento es erróneo y genera efectos negativos que confunden y dificultan una adecuada conceptualización. Sobre esa base, la distinción se valora en torno a un campo de casos más acotado, relativo a los problemas que asisten a la identificación de una unidad de delito de carácter homogéneo, una parte de los casos tratados en el concurso aparente de leyes penales y en el supuesto propio del concurso ideal de delitos, materias en las que la noción de unidad de hecho no se propone con un contenido uniforme.
\end{abstract}

Palabras clave: Unidad de hecho, concurso de delitos, concurso ideal, concurso homogéneo.

ABSTRACT: The traditional legal theory systematizes concurrent offenses distinguishing between unity and plurality of facts. This distinction was predominant in the twentieth century, highlighting the possibilities to identify connections between unitary cases and the construction of the perpetration of one single crime. This article criticizes the focus of this traditional approach, describing its negative impact at the moment to propose accurate definitions of the categories involved. On that basis, the distinction is valued around a narrower field of cases, related to the problems that assist in the identification of a homogenous crime unit, a part of the cases dealt with in the apparent competition of criminal laws and in the case of the ideal crime concurrence, matters in which the notion of de facto unity is not proposed with a uniform content.

Keywords: Unidad de hecho, concurrent offenses, ideal crime concurrence, homogenous crime concurrence.

\section{PLANTEAMIENTO DEL PROBLEMA}

En la teoría del concurso de delitos se suele asignar un papel importante, e incluso estructural, a la tarea consistente en identificar si en un determinado supuesto de hecho concurre una única acción o varias ${ }^{1}$. Dicha comprensión se asocia a la creencia de que una

\footnotetext{
* Abogado. Doctor en Derecho, Universidad Pablo de Olavide, Sevilla. Profesor Asociado de la Facultad de Ciencias Jurídicas y Sociales de la Universidad de Talca. Dirección postal: Santa Elena 2222, San Joaquín. Dirección electrónica: frmaldonado@utalca.cl. Número Orcid: 0000-0003-2361-3750. El texto forma parte del proyecto FONDECYT Regular No 1170276, financiado por Conicyt, del cual el autor es investigador responsable.

1 Categórico Mezger (1958) p. 333; Escuchuri (2004) p. 95; Jescheck y Weigend (2014) p. 1059; Roxin (1997) p. 943; ZaFFARONI et. Al (2002) pp. 853-854.
} 
unidad de acción refleja una unidad de delito $^{2}$, de forma que la pluralidad de acciones necesariamente dará cuenta de un concurso de infracciones ${ }^{3}$. Se asume por ello, apresuradamente, que una pluralidad de acciones lleva a una pluralidad de sanciones, pues se tratará de varios delitos. Y por lo mismo, se asume que una sola acción debiese llevar a la imposición de una única sanción y a la identificación de un único delitó ${ }^{4}$.

Lo dicho, más allá del entendimiento generalizado, resulta profundamente desacertado, pues se parte de una premisa errada. Delito solo es acción en cuanto la presupone, lo que en modo alguno implica que ambos conceptos se identifiquen ${ }^{5}$. Hay que tener en cuenta que si aquello que cuenta como definición de la acción se identifica con las propiedades de un determinado delito, resultará correcto afirmar que habrá tantos delitos como acciones llevadas a cabo ${ }^{6}$. No obstante, eso será así pues, a fin de cuentas, la relación de ambos conceptos será íntegramente circular ${ }^{7}$. Con ello, parece claro que una conceptualización de este tipo resulta inútil, pues bajo dichos caracteres no es posible que la expresión "acción” pueda llegar a cumplir función alguna, en especial, si se pretende que ayude a precisar si se aprecia un único delito o varios, por cuanto acción y delito pasan a ser sinóni$\operatorname{mos}^{8}$. Por esta razón, el uso de la expresión acción debe ofrecer un contenido diverso si se desea que cumpla una función en la teoría concursal.

El término delito da cuenta de una calificación de comportamiento9 ${ }^{9}$, que se refleja en torno a un sustrato empírico ${ }^{10}$. Y solo desde esta perspectiva se puede admitir que todo delito es acción en relación al suceder externo, material o empírico, lo que no significa que sea igual o equivalente a una acción o sustrato. Así, la cantidad de delitos a identificar

\footnotetext{
2 Se trata de la percepción imperante en la primera mitad del siglo XX asociada a la llamada "teoría de la unidad”. Sobre su desarrollo véase ArCE (1996) pp. 100 y ss.; SANZ (1986) pp. 144 y ss.; y RoIg (2011) p. 34. En extremos se sostiene que el delito "es la acción material" ejecutada (Bustos (1962) pp. 32 y ss.; CARAMUTI (2018) p. 33, 35 y 209; CÁrdenas (1973) pp. 37 y ss.; Etcheberry (1964) pp. 11-12; Zaffaroni Et. Al (2002) p. 865, y, en Alemania, Frister (2016) p. 666; Jescheck y Weigend (2014) p. 1073.

3 Por todos, Cury (2007) p. 649; Así se explica la propia denominación del concurso "ideal” concebida como una "abstracción irreal" (Roxin (1997) p. 941; LuRATi (2018) p. 118) instituto que cumple la función de "clarificar" en la sentencia la concurrencia de más de un delito, no obstante, se trata de una única acción. Sobre dicha función Jescheck y Weigend (2014) p. 1073; Stratenwerth (2005) p. 552.

${ }^{4}$ La idea se refleja en la noción "qua delicta tot poenae". Bustos (1962) p. 102-105; CÁrdenas (1973); FonteCilla (1956) pp. 78-79; Ortiz y Arévalo (2013) pp. 317 y 346 (actualmente) y SANZ (1986) pp. 44 y 46-51.

5 Lo relevante a dicho respecto es que solo una acción o conducta ofrece una dimensión de sentido, que habilita a un juicio o atribución. FletCher (2008) p. 363; Silva (2003) p. 52.

6 Cuerda (1997) pp. 341-354; Jakobs (1997) p. 1079; Jescheck y Weigend (2014) p. 1060; Mañalich (2005) p. 1150; Mir (2005) pp. 626-627; NinO (1972) p. 43; RoIG (2011) pp. 136-137 (con cita de otros autores de referencia); SANZ (1986) p. 213; Vives (1981) p. 10; ZAFFaroni Et. Al (2002) p. 857.

7 Mañalich (2018a) pp. 83-84; SAnZ (1986) p. 148.

8 Veremos que tampoco es útil en el campo del concurso ideal, pues se hace imposible sostener una pluralidad de delitos en unidad de acción (o hecho). Sanz (1986) p. 213; Jescheck y Weigend (2014) p. 1060; Van WeeZEL (2020) p. 7; VIVES (1981) p. 10.

9 Cid (1994) p. 49; Escuchuri (2004) p. 26; Novoa (2005) p. 221; Pessoa (2018) p. 34; Peñaranda (1991) pp. 31-32); ViVES (1981) p. 16.

10 FernÁNdez (2013) pp. 36 y 37; MaÑAlich (2018b) pp. 172-174, respecto de lo que cuenta como "una única instancia de realización”; Mir (2005) pp. 625-626; Politoff et al. (2003) p. 445; SAnz (1986) p. 152 (relativo a "las actividades mediante las cuales se realiza el tipo"); Welzel (1993) p. 265.
} 
en un supuesto de hecho estará condicionada por la cantidad de calificaciones aplicables, con independencia de la cantidad o clase de movimientos, aconteceres o efectos materiales posibles de afirmar o reconocer en el mundo ${ }^{11}$. De esta forma, se pueden advertir delitos (únicos) configurados a partir de varios movimientos o efectos -acciones "en sentido natural"12 - y varios delitos en torno a un único acontecer natural ${ }^{13}$, lo que dependerá a fin de cuentas de las propiedades que los describan ${ }^{14}$.

De lo dicho se extraen dos conclusiones relevantes de tener en cuenta. Primero, que el rendimiento de la noción "acción", a efectos de la identificación de un delito o de su cuantificación, depende de que exprese un contenido diverso al que ofrecen las respectivas descripciones de delito; y segundo, que la definición de acción juega un papel mucho más modesto del que se suele atribuir en la teoría concursal ${ }^{15}$, como tarea trascendental ${ }^{16}$. En concreto la noción de "acción" solo podría resultar relevante en este ámbito en torno a tres problemáticas en particular: primero, para determinar si estamos frente a un caso de unidad delictiva (una "única acción") en atención a la relación que ofrecen diversas clases de tipos penales concurrentes en el campo del "concurso aparente de leyes penales"; segundo, para determinar si un delito es ejecutado una única vez o varias en torno a ejecuciones delictivas de la misma clase (unidad jurídica en delitos homogéneos); y, tercero, para identificar el presupuesto de un concurso ideal de delitos ${ }^{17}$.

Desde esta perspectiva, y solo desde esta, es posible entender que es correcta la afirmación que sostiene que la noción de acción que se utiliza (o debe utilizar) en el concurso de delitos no es la misma de la teoría del delito ${ }^{18}$. No obstante, el uso o contenido de lo que se entienda por unidad de acción podría perfectamente ser diverso en cada una de las cuestiones planteadas, en tanto su precisión está condicionada por la función que dicha

\footnotetext{
11 Además, la dimensión naturalística no ofrece parámetros idóneos para "recortar" el mundo en fragmentos que cuenten como una acción, pues ello siempre dependerá de un concepto y, con ello, de una interpretación. Arce (1996) p. 60; Caramuti (2018) p. 37; Caruso (2018) pp. 25 y 26; Cuerda (1997) pp. 346-347; MañaLICH (2018a) p. 84; STRATENWERTh (2005) p. 550. Así, criterios como la dimensión espacio temporal, el contexto o el carácter ininterrumpido de una ejecución, no son idóneos pues aluden a nociones tan amplias y variadas que carece de toda utilidad. ArCe (1996) pp. 59-60; Escuchuri (2004) pp. 368-374; Frister (2016) p. 674; SuÁreZ (2001) p. 74; VAN WEEZEL (2020) p. 10.

12 Estos casos se identifican como "unidad jurídica de acción", en cuanto reunión de varias acciones "en sentido natural”. EtCheberRy (1964) pp. 5-6; Fontecilla (1956) p. 60.

13 Garrido (2007) p. 335; Mañalich (2018a), pp. 82 y 83; Matus (2002) p. 27. Lo que cuenta como acción natural suele estar asociado a una definición amplia o general, aplicable a cualquier clase o forma de acción. Por ello se los interpreta como parte de la realidad (NovoA (2005) p. 222) a pesar de que también dependen de una descripción. Caruso (2018) p. 25; García (1995) p. 12; Stratenwerth (2005) p. 536.

14 Cid (1994) p. 49; Mañalich (2018b) p. 173.

15 Caramuti (2018) p. 40; García (1995) p. 121 y Caruso (2018) p. 23-24; Escuchuri (2004) pp. 354-355.

16 Garrido (2007) p. 336; Cuerda (1997) pp. 344-345; Jescheck y Weigend (2014) p. 1059; Mezger (1958) p. 333; Roxin (1997) p. 943; ZafFaroni Et. Al (2002) pp. 853 y 854. Sobre lo extendido de dicha asunción Cuello (1979) p. 50; Escuchuri (2004) p. 95.

17 Con matices, Caruso (2018) pp. 23-24; García (1995) p. 121; Mir (2005) p. 624; Zaffaroni Et. Al (2002) p. 857. Implícito en MaÑAlich (2018a) pp. 83-84; MaUrach et al. (1995) p. 525.

18 En este sentido, por todos, JaKobs (1997) p. 1074; SAnz (2012) p. 40; Palma (2004) p. 110; Roxin (1997) p. 944.
} 
noción está llamada a desempeñar en cada caso $^{19}$, hipótesis que sostenemos y que procuraremos justificar en las líneas que siguen ${ }^{20}$. Así, analizaremos la posibilidad de establecer una relación de identidad en las normas extraídas de los respectivos enunciados concurrentes en algunas hipótesis de concurso aparente de leyes penales (en aquellas en que lo dicho resulta particularmente discutible); sostendremos una noción más cercana a la idea de "realización" en torno a los casos de unidad de delito; y, finalmente, recurriremos al contexto en que se expresa o ejemplifica dicha realización para tratar el supuesto que define el concurso ideal.

\section{UNIDAD DE ACCIÓN EN EL LLAMADO CONCURSO APARENTE DE LEYES}

Lo primero a tener en cuenta es que la tradicional creencia de que los problemas del concurso aparente de leyes penales se refieren a casos de unidad de delito ${ }^{21}$ es altamente discutible $^{22}$. Basa advertir que desde siempre se han incluido en dicho ámbito supuestos problemáticos relativos a una pluralidad de acciones o hechos, particularmente en el tratamiento de los actos anteriores y posteriores copenados ${ }^{23}$, denominados históricamente por ello como hipótesis de "concurso real impropio" ${ }^{24}$. Por otro lado, la doctrina tradicional y dominante en nuestro medio caracteriza el problema que proponen estos casos en torno a relaciones que ofrecen las normas incriminatorias entre $s^{25}$, lo que sitúa las cuestiones a resolver en un ámbito lejano a la necesidad de distinguir si se trata de una unidad o pluralidad de acciones (o hechos). Así, tras el infanticidio solo se podría reconocer un delito, pues la relación de especialidad (entre las normas) lleva descartar la aplicación del homicidio y del parricidio, en tanto estas prohibiciones no habrían sido establecidas para esos casos. A lo sumo, la consideración de una única realización o acción punible aportaría un indicio que favorece la conclusión de que, en dichos casos, los principios de solución ayudan (vía hermenéutica ${ }^{26}$ )

19 Escuchuri (2004) p. 376; García (1995) p. 121; Mañalich (2018a) pp. 83-84; Zaffaroni Et. Al (2002) p. 857; Caruso (2018) pp. 16 y 17. Con menor precisión Cuerda (1997) pp. 353-354. Sobre la relevancia del aspecto funcional (a este respecto) véase GONZÁLEZ (2015) p. 73.

20 La aclaración es relevante pues se suele proponer una única noción que es utilizada en forma indistinta en torno a todas las cuestiones planteadas. Se constata por EsCUCHURI (2004) p. 354 y 355; Frister (2016) pp. 669 y 673; Maurach et al. (1995) p. 525. Cuerda (1997) pp. 353-354 explica la confusión como efectos de la primacía histórica de la "teoría de la unidad" (el concurso ideal hay un solo delito).

21 La visión tradicional durante el Siglo XX favoreció la idea de que este instituto es relativo a "casos de unidad de acción” (Cury (2007) p. 667; Muñoz (1986) pp. 369-371; NovoA (2005) pp. 233, 248-249), por lo cual los problematiza por oposición al concurso ideal (Bustos (1962) p. 71; ETCHEbERry (1964) pp. 12-14; GARRIDO (2007) p. 351; Fontecilla (1956) p. 61. Se llega incluso a sostener la máxima "in dubio pro concurso ideal" (Mañalich (2018b) pp. 195 y 206).

22 Cury (2007) p. 667; Etcheberry (1997) p. 122.

23 Jakobs (1997) p. 1049; Maurach et al. (1995) pp. 583 y ss.; Palma (2004) pp. 123 y ss.

24 Mañalich (2018b) pp. 195 y ss.; Mañalich (2005) pp. 1044-1050. La idea de los "actos copenados" también son casos de unidad de acción, en cuanto forman parte de la misma ejecución, es altamente discutible. Sobre ello Frister (2016) pp. 687-688.

25 Fontecilla (1956) p. 61; Maurach et al. (1995) pp. 553 y 561.

26 La idea es usualmente referida como "interpretación sistemática”. FonteCILla (1956) p. 91; RuIz (2015) p. 196; Labatut (1993) p. 47; Ortiz y Arévalo (2013) p. 362; Rettig (2017) p. 271. La interpretación re- 
a identificar una única infracción (o delito ${ }^{27}$. Por ello, se advierte tras dichas situaciones un concurso de leyes (esto es, de enunciados), pero no de normas, ni de delitos ${ }^{28}$.

No obstante, el tratamiento de la unidad de acción pareciera más relevante y complejo para la tendencia que objeta esta forma de concebir y resolver los problemas del concurso aparente, bajo la comprensión de que se trata de un problema que afecta a la determinación de la pena ${ }^{29}$, referido a la aplicación de las normas de sanción (y no de un problema referido a las conductas incriminadas y su interpretación o regulación ${ }^{30}$ ), tesis que en la actualidad cuenta paulatinamente con el parecer dominante de la doctrina y que ya goza de reconocimiento en nuestro medio ${ }^{31}$. Dicha comprensión sostiene que en estos casos los imperativos comprometidos concurren (esto es, que se trata de un auténtico concurso de delitos $^{32}$ ) y resultan coincidentes en su sentido e inspiración ${ }^{33}$, lo que sin embargo no tiene por qué llevar necesariamente al uso de todas y cada una de las reglas de sanción previstas

solvería preventivamente cualquier potencial conflicto entre las normas. Lo constata en esos términos GUASTini (2016) pp. 258 y 259; GUASTINI (2011) pp. 111 y 112; ItURRALde (1987) p. 346 (otros lo califican como una "reinterpretación" conforme se detalla en Huerta (2003) p. 201; Moreso (2010) p. 119; Pérez (2009) pp. 14-15 y 41 y ss.). ello ocurriría durante el proceso de identificación de las normas a partir de los enunciados (Huerta (2003) p. 176; Lifante (2015) p. 191; Navarro y Moreso (1996) p. 136) y permitiría sostener que cada norma cuenta con su propio ámbito de casos regulados. Su interacción se define por ello bajo relaciones de heterogeneidad (EscuCHURI (2004) pp. 43 y ss.; GARCía (1995) p. 215.). Se considera en ello que los enunciados son el continente de las normas, de una o varias de ellas, de forma unitaria o en conjunto (CASTELló (2000) p. 8; Escuchuri (2004) p. 21; Huerta (2003) p. 21) lo que supone aceptar (correctamente) que norma y enunciado son algo diverso. Bustamante (2010) p. 85; Ródenas (2015), p. 15; Ratti (2013) p. 129.

27 Constituye la forma de comprensión dominante en Chile como bien destaca Ossandón (2018) p. 970, nota 71 (con referencias bibliográficas) y Muñoz (1986) p. 367. En esa línea CuRY (2007) pp. 206 y 668; ETCHEBERRY (1997) p. 122; Garrido (2007) p. 335-336; Labatut (1993) p. 174; Novoa (2005) p. 249; Ortiz y ArÉVALO (2013) p. 354. En su tiempo, Bustos (1962) p. 72 y Fontecilla (1956) pp. 52 y 91.

28 Cury (2007) p. 667; Fernández (2013) p. 27; Etcheberry (1997) p. 122. Lo dicho explica el uso en otros contextos (como el alemán) del término "unidad de ley" y antes de "concurso impropio" (STRATENWERTH (2005) p. 540), en tanto enfatiza que las leyes desplazadas no concurren (Frister (2016) p. 679; JESCHECK y Weigend (2014) pp. 1092 y 1093). Lo mismo ocurre en el uso del "concurso de leyes" como opuesto a "concurso de delitos" (Fernández (2013) p. 27), y con el propio calificativo de "aparente" que suele acompañar (Ortiz y Arévalo (2013) p. 354). Sobre la terminología Mañalich (2005) p. 1039.

29 Mañalich (2018b), pp. 175 y ss.; Antes, Mañalich (2005) pp. 1040, 1173-1174. En España García (1995) p. 209; Mir (2005) p. 638; En Alemania, Maurach et al. (1995) p. 557 y 561; Implícito en Frister (2016) p. 680. Como problema de "punibilidad" Palma (2004) p. 36. Sobre el nexo entre norma de sanción o secundaria y reglas de aplicación (adjudicación) Rodríguez, p. 192 y 193.

30 Mañalich (2005) p. 1023; Ossandón (2018) p .969; Prams (2010) p. 461. Asimismo, tempranamente, EtCHEBerry (1964) pp. 24-25 (como parte de "la aplicación de la ley").

31 En España la doctrina clásica fue influyente hasta hace poco (Matus (2002) pp. 48 y 49; SANZ (2012) p. 16; Asimismo, SuÁrez (2001) p. 64 (con cita de autores) pero se reconoce que tiende al abandono (Mir (2005) p. 638). Se constata lo dicho en Castelló (2000) p. 7 y 14; Escuchuri (2004) pp. 13-15; Peñaranda (1991). En Alemania, lo mismo (Matus (2001) pp. 45 y ss.), favoreciéndose en la actualidad el reconocimiento del concurso efectivo (García (1995) p. 135; Stratenwerth (2005) p. 540). En Chile, Mañalich (2005) pp. 1023, 1039, 1040 y 1193; antes, Mañalich (2004) p. 499; y tempranamente Matus (2005) p. 466. En Argentina, Nino (1972) p. 48 y 66; PeSSOA (2018) p. 83.

32 Castelló (2000) p. 7; Escuchuri (2004) pp. 13-15; García (1995) p. 135; Matus (2000) pp. 74-75. Matus (1999) p. 79; Mañalich (2005) p. 1023, 1039, 1040 y 1193; Maurach et al. (1995) pp. 557 y 561; PesSOA (2018) p. 83.

33 ZorZetTo (2013) p. 395. 
para su ejecución individual. Ello es así pues dicha aplicación conjunta (por definición imprevista) podría resultar objetable (en su interacción contingente) bajo la forma de un conflicto de normas (de sanción) ${ }^{34}$. Frente a ello se acude al recurso que ofrecen las reglas de preferencia, a fin de hacer uso solo de algunas de estas normas por sobre las otras, que resultan por ello excluidas de consideración, aplicable cuando de esa forma se da cuenta de la totalidad de los aspectos (o propiedades) del hecho que resultan relevantes de considerar, sin duplicar ninguno ${ }^{35}$.

Las ventajas de esta tesis son considerables, especialmente si se tiene en cuenta los déficits estructurales que se plantean (como objeción) respecto de la construcción tradicional ${ }^{36}$. No obstante, plantea efectos que no siempre resultan sencillos de asumir, en tanto suelen resultar contraintuitivos, especialmente en casos en que pareciera altamente complejo afirmar un auténtico concurso de delitos, y en los que resulta fundamental la consideración de que se trata de supuestos configurados en torno a una misma y única acción. Como ejemplo reiteramos el caso del infanticidio, pues no resulta sencillo convencer que quien da muerte a un hijo antes de las 48 horas de vida ha cometido realmente tres delitos (homicidio simple, calificado e infanticidio) precisamente teniendo en consideración el que ha ejecutado una sola acción. Y lo propio sucede en la apropiación ejecutada en un domicilio con fractura y en forma violenta (contra las personas), pues todo indica que se trata solo de la ejecución de un único delito de robo.

Lo dicho se extiende a buena parte de los casos referidos a especialidad (más precisamente a los que se configuran por especificación ${ }^{37}$ ) y, particularmente, en todos los supues-

\footnotetext{
34 Es fundamental tener en cuenta que todo enunciado que contiene una norma condicional (como las normas penales primarias) admite un doble proceso de identificación, referido, por un lado, a una norma de conducta (dirigida al ciudadano) y, por otro, a una "norma de sanción" (dirigida al adjudicador). MAÑAlich (2005) p. 1192 y, algo más general, en AlONSO (2018) p. 110. La misma distinción se propone bajo la denominación de norma primaria y secundaria (RetTig (2017) pp. 37-41)

35 Cid (1994) p. 40; GarCía (1995) pp. 48 a 53, 178, 181 y 183,

36 Se critica, en lo fundamental, que se confunde la tarea consistente en la interpretación de las normas con la operación relativa a su sistematización (Alonso (2018) pp. 74, 75, 94 y 97; GUASTINI (2011) pp. 111 y 112 ; ItURRALDe (1987) pp. 32 y 35; RatTi (2013) p. 121. Bulygin (1991) p. 483); y que resulta inconsistente con los criterios que dominan la resolución de los problemas de comunicabilidad, error y participación en el delito, pues dichas dinámicas presuponen la concurrencia de tipos básicos y figuras agravadas, calificadas o privilegiadas (Peñaranda (1991) pp. 136-179 -fundamental-; Ossandón (2018) pp. 971-972; Escuchuri (2004) pp. 48-56; Pessoa (2018) pp. 100 y ss. Asimismo, con respecto al error, Matus (1999) pp. 82-105; Mañalich (2015), pp. 193-194); impide el "resurgimiento de la norma preterida" cuando la norma preferente no se aplica por causas extra sistemáticas (Matus (2002) pp. 41 y ss.; Maurach et al. (1995) p. 557; Palma (2004) p. 21 y 233; Peñaranda (1991) p. 67; Roxin (1997) p. 1021 y, con matices Nino (1972) p. 52.), como en la tentativa calificada (Matus (2002) pp. 43, 44 y 61; Roxin (1997) p. 1018; PessoA (2018) pp. 105 y ss..); y, finalmente, obliga a una reinterpretación en base a relaciones genéricas construidas en abstracto en sentido extensional (RATti (2013) p. 244; Castelló (2000) p. 119) y anticipadas, con resultados incompatibles con el mandato de exhaustividad. Por otro lado, la tesis de la aplicabilidad tiene la ventaja de resultar compatible con la conceptualización de instituciones fundamentales de los sistemas jurídicos (como la validez, eficacia, aplicabilidad y derrotabilidad de las normas) que resultan difíciles de sostener desde la perspectiva tradicional y que no son sencillas de obviar en la actualidad (Por todos, NAVARRO y MORESO (1996) p. 138.)

37 Una parte de la doctrina distingue los casos señalados (especificación) de los de especialidad "por adición". Los primeros se forman por la precisión de algún elemento del tipo general; los segundos, agregando un elemento no considerado. Al respecto véase García (1995) p. 322-323.
} 
tos en que concurren dos o más tipos penales que constituyen especificaciones alternativas y diversas de una figura básica común ${ }^{38}$, en los que nadie discute la solución del concurso aparente (esto es, la aplicación de una preferencia y la correlativa exclusión). En concreto, no se trata de negar, rechazar o controvertir el que un mismo supuesto pueda admitir una pluralidad de calificaciones jurídico-penales ${ }^{39}$, de forma que puede perfectamente servir de recipiente a una pluralidad de delitos. Se trata más bien de constatar que en estos casos dicha pluralidad resulta cuestionable, pues el sentido que ofrece la regulación pareciera indicar sin lugar a dudas que se trata de casos unitarios, con base en el indicativo que aporta el que indiscutiblemente se trata de una sola acción a valorar. De ahí la relevancia que tienen a los efectos que nos convocan en este desarrollo en particular.

El que todos estos casos hayan podido ser regulados en forma conjunta o separada o a través del uso de circunstancias modificatorias reafirma la idea de que su expresión formal no es más que "una opción regulativa del legislador" que no puede ser interpretada como una decisión relativa a "crear un nuevo o nuevos delitos". La pluralidad por ello no sería más que aparente, tal cómo sugieren los términos de la doctrina clásica. Lo dicho se confirmaría además si se tiene en cuenta que los fallos que recaen en este tipo de casos no suelen dejar constancia de la pluralidad descrita a la hora de condenar, constituyendo una práctica casi unánime en los casos de especialidad, y que contrasta con la forma más usual bajo la cual los jueces actúan en los demás casos en que se reconoce un concurso aparente (pues sueñen dejar constancia del problema y de la solución $)^{40}$. Esta misma lectura se apoya en el hecho de que en estos casos se puede anticipar el potencial conflicto ${ }^{41}$, de forma que no se presenta como una eventualidad o en términos contingentes, que debiese ser lo propio de las hipótesis de concurso aparente. Así, todo parricidio será, a su vez, un homicidio; y todo robo, un hurto, de forma que siempre sería posible evitar una potencial redundancia con base en las técnicas que ofrece la interpretación (que en particular buscaría además plasmar lo que se entiende es la pretensión del propio legislador $)^{42}$.

Lo dicho hasta el momento obligaría a profundizar el debate entre ambos planteamientos pues resultaría indispensable ofrecer criterios que permitan distinguir (y en su caso exceptuar) este tipo de casos del tratamiento general, en la medida que se desee mantener la orientación propuesta bajo la tesis de la aplicabilidad. Y -lo relevante- es que en dicha tarea sería fundamental tomar postura acerca de cuándo es posible sostener una unidad en la acción ejecutada que "obligue" a identificar una unidad de delito, a pesar de la múltiple tipicidad formal. No obstante, creemos que nada de eso resulta necesario, según pasamos

\footnotetext{
38 Este caso es considerado uno de los más discutidos en doctrina del concurso (GARCía (1995) p. 372; EsCUCHURI (2004) pp. 270-282. Cabe destacar que en Alemania se los califica de preferencia como un concurso ideal, si bien dicho modelo prevé una solución penológica idéntica a la que se concede al concurso aparente (la absorción simple y no agravada. Sobre esto último GarCía (1995) p. 373; STRATENWERTH (2005) p. 541.

39 Por todos, Ossandón (2018) p. 965.

40 Frister (2016) p. 682.

41 Al respecto NovOA (2005) p. 254; PeSSOA (2018) p. 121; SANZ (1986) p. 122.

42 En este sentido se trataría de casos asimilables a los de "subsidiariedad expresa" y a aquellos que se pueden interpretar como hipótesis concursales especialmente reguladas (como sucede en los delitos complejos). MAÑALich (2005) p. 1026; Garrido (2007) p. 336; Roxin (1997) p. 1002; STRATENWERTH (2005) pp. 542.
} 
a desarrollar en las líneas que siguen. En lo fundamental basta con advertir que la propia identificación de una pretensión tras la forma que adopta la consagración de la decisión del legislador permite advertir que no hay nada en estos casos que incida concretamente en el campo de la determinación de los imperativos de conducta que se regulan, sino que solo expresa una decisión relativa a la manera como el legislador pretende que estos casos sean sancionados ${ }^{43}$. La forma del respectivo enunciado (o de los enunciados) no constituye en estos casos un elemento de juicio que sirva para sostener una interpretación sobre lo que cuenta como delito, ni sobre cuántos de ellos se pueden considerar concurrentes, sino que solo refleja lo que el legislador dispone para su penalización o, lo que es igual, lo que decide aplicar como regla de sanción para los eventos en que se constate su comisión ${ }^{44}$.

A este respecto conviene tener en cuenta que los casos referidos a "tipos mixtos alternativos" ${ }^{45}$ o con pluralidad de hipótesis de comisión se presentan con una estructura similar, construida en términos inversos. En ellos, se trata de una pluralidad de conductas (y en su caso, de acciones) que solo darán lugar a una misma y única regla de sanción por expresa disposición del legislador, quien pareciera reunirlos en un solo precepto o enunciado precisamente a dichos efectos ${ }^{46}$. La constatación es altamente relevante pues respalda contundentemente lo dicho, toda vez que demuestra que en estos casos la forma que asume el enunciado no se vincula en modo alguno a la constatación de una unidad o pluralidad de acciones o conductas (que acá no se discute), sino que encuentra su sentido preciso en una definición sobre pena (es decir, sobre la regla de sanción aplicable). El ejemplo sirve además para resaltar que la noción de delito solo expresa una calificación de comportamiento que se identifica con la descripción de un "tipo" o clase de conducta ${ }^{47}$, de forma que la concurrencia, esto es, el "concurso", no es más que la constatación de una pluralidad de "casos-tipo" que se constatan en torno a un sustrato. De esta forma, nada hay que objetar

\footnotetext{
43 Así, Etcheberry (1964) p. 71. Lo propio sucede con las cláusulas de subsidiariedad expresa y en los delitos complejos (García (1995) p. 119; Mañalich (2005) p. 1026), en los que solo se advierte una definición sobre pena. Por ello, las cláusulas señaladas no se interpretan como "elementos negativos del tipo", sino como reglas de aplicabilidad (de pena). En este sentido, Mañalich (2018b) pp. 193. Ossandón (2018) p. 972. Así, en Chile, el sentido de la cláusula prevista en el art. 391 del CP no es excluir los casos de parricidio de la prohibición contenida en el homicidio simple o calificado, sino solo exigir que esos "homicidios" -que lo son- se penalicen con una regla de sanción diversa (en particular, con la prevista para el parricidio).

${ }^{44} \mathrm{La}$ operatoria propuesta coincide con uno de los usos que se atribuyen al denominado "elemento sistemático" como criterio de interpretación (GUASTini (2015) p. 44; NovoA (2005) p. 136; RetTig (2017) pp. 269270). Se trata de una práctica que suele ser objetada como ejercicio hermenéutico, teniendo en cuenta lo que debiese ser objeto de interpretación es el contenido de un enunciado, y no su forma, ubicación u otros elementos semejantes. Por otro lado, hay que tener en cuenta que la interpretación no puede servir de base para concluir la derogación total o parcial de otra (GUASTini (2011) pp. 111 y 112) o su invalidación (MarTínez (1993) pp. 81), que es lo que sucede cuando se procura modificar su ámbito de cobertura. Lo dicho es posible, pero no a partir de la hermenéutica Diez (1994) p. 399; Ferrer y Rodríguez (2011) p. 164; Guastini (2011) ; Huerta (2003) pp. 160 y ss.; ZoRZETTo (2013) p. 396. Sobre la relación entre cobertura de una regla y su validez, véase, por todos, Pérez (2009) p. 17. En cualquier caso, constituiría una "invalidez parcial” (en tanto "recorta” una parte de los supuestos) como detalla EscuCHuri (2004) pp. 15 y ss.

45 Ortiz y Arévalo (2013) p. 319.

46 Cury (2007) p. 653; García (1995) p. 115-117 y 141.

47 Matus (1999) p. 99 y 100; Novoa (2005) p. 221. Implícito en Escuchuri (2004) p. 26; PessoA (2018) p. 34; Peñaranda (1991) pp. 31-32; Politoff et al. (2003), p. 445: Vives (1981) p. 16;
} 
a la afirmación de tantas calificaciones y delitos como unidades o tipos de conducta sean satisfechos en un mismo supuesto. El que resulte contraintuitivo es algo que se explica por la errónea y arraigada tradición, desarrollada en el transcurso del siglo XX, que identifica el delito con una expresión material centrada en la acción (entendida como "natural") y que, en buena medida, se encuentra hoy en día ampliamente superada ${ }^{48}$.

Por su parte, el que la práctica judicial no suela dar cuenta formal de la pluralidad delictiva admite también una reflexión, considerando que se trata de un uso que solo es propio de los casos de especialidad y no de todos aquellos que se resuelven como concursos de leyes (o "concursos aparentes") de manera uniforme. Esta práctica no parece encontrar sus razones en una distinción o característica de carácter material o sustantiva, sino que se explica por cuanto se trata de situaciones (relativamente escasas) que ofrecen la particularidad de que la redundancia y la preferencia pueden preverse por anticipado ${ }^{49}$, con base en la especial forma que presenta la decisión legislativa que los regula ${ }^{50}$. No obstante, y a pesar de ello, no se puede negar que conservan plenamente la característica de constituir una conjunción (concurrencia o "concurso") de carácter contingente o eventual, más allá de lo que parece ${ }^{51}$. Si bien lo señalado debilita el reconocimiento de dicho carácter cuando se satisfacen los presupuestos de la figura especial (pues por definición son hipótesis en las que siempre se cumplirá con el contenido de la norma general ${ }^{52}$ ) no es posible obviar que constituye una condición o cualidad que se mantiene intacta en los demás casos, por el simple hecho de que no es posible anticipar aquellos en los que puede concurrir el tipo general de forma aislada (sin que se satisfaga al mismo tiempo el tipo "especial"). Así, la posibilidad de una concurrencia sigue siendo una eventualidad (una contingencia), pues depende de que el supuesto de que se trate incluya las propiedades que lo especifican o califican (previstas en las reglas "especiales") 53 , lo que no se puede advertir, intuir y menos afirmar por anticipado $^{54}$. Constituye por ello un tipo de conflicto de normas que mantiene todos sus elementos definitorios en cuanto tal (incluyendo el carácter contingente), y que, en tal virtud, se identifica en doctrina como un conflicto de carácter "total/parcial" 55 . De esta forma, todo indica que es esta peculiaridad lo que explica la mencionada practica judicial, pues, tratán-

48 Bustos (1962) pp. 32 y ss.; Caramuti (2018) pp. 33, 35 y 209; Etcheberry (1964) pp. 11-12; ZafFaroni Et. Al (2002) p. 865, y, en el contexto alemán, Frister (2016) p. 666; Jescheck y Weigend (2014) p. 1073. Sobre la "superación” aludida Hilgendorf y Valerius (2017) p. 320; Vives (1981) p. 16).

49 En ese sentido se sostiene -de forma apresurada- que en ellos la especialidad se advierte a partir del contraste abstracto de las normas. Al respecto NovoA (2005) p. 254; PessoA (2018) p. 121; SANZ (1986) p. 122.

50 Cabe destacar que lo dicho también sucede en los delitos complejos y, por definición, cuando se hace uso de una cláusula de subsidiariedad expresa. Por ello, como destaca JAKOBS (1997) p. 1056, "resultan más sencillos de resolver".

51 Mañalich (2018b) pp. 197-198, quien por ello los define como casos de "redundancia circunstancial intrínseca”.

52 Peñaranda (1991) p. 36.

53 Lo destacan, a los mismos efectos, JESCHECK y WeIGEND (2014) p. 1095.

$54 \mathrm{Al}$ respecto véase la forma como ZorzetTo (2013) p. 392 define este tipo de relaciones.

55 Así, Diez (1994) p. 396. Los conflictos entre normas pueden ser caracterizados a este respecto según el tipo de concurrencia que se proponga desde los enunciados respectivos. En estos casos la relación "total / parcial" implica que en una dirección siempre habrá conflicto, lo que resulta aleatorio en la otra. Asimismo, la relación "parcial / parcial", supone que el carácter problemático es contingente respecto de ambas (de forma que, en relación a ambas reglas puede existir conflicto, según las circunstancias). Sobre la categorización véase RuIZ 
dose de la concurrencia de las figuras especiales el concurso se presentará como algo "necesario" o predecible, permitiendo anticipar el conflicto y la preferencia que lo resuelve. Así se explica también por qué dicha práctica no se refleja en modo alguno en la amplia mayoría de supuestos diversos en que se afirma el "concurso aparente" en forma indiscutida, y en los que en la sentencia se suele dejar constancia de la concurrencia y de la institución.

De esta forma, nos parece que nada hay tras estos casos que lleve a alterar los elementos bajo los cuales cabría caracterizar a esta institución (concurso aparente de delitos) o definir la naturaleza del problema que ofrece, ni de su solución, confirmando con ello que en este campo carece por completo de relevancia el tratamiento de lo que cabe considerar como una unidad de acción (o como varias).

\section{CASOS DE UNIDAD NATURAL O JURÍDICA DE ACCIÓN}

Por otro lado, hemos ya anticipado que los casos en que se compromete la concurrencia de un mismo y único tipo de hecho punible también resultan problemáticos, por la sencilla razón de que no siempre es sencillo determinar cuándo se puede afirmar que ha sido realizado en una única vez o en más de una oportunidad, configurando en este último caso un concurso real homogéneo. La entidad de la dificultad se advierte si tenemos en cuenta que los casos que se tematizan en la doctrina en torno a la llamada unidad de acción homogénea ${ }^{56}$ (y extremos como casos de "delito continuado" ${ }^{57}$ ) son los que hasta el momento ofrecen más soluciones parciales y resultan más discutibles ${ }^{58}$. Destacan en particular las situaciones denominadas de ejecución progresiva, sucesiva o iterativa del tipo ${ }^{59}$,

(2015) p. 59 y ss.; HuerTa (2003) pp. 74 y ss. Los desarrollos se suelen exponer en torno a antinomias, pero se replican en los mismos términos respecto a las redundancias (NINO (1995) pp. 274-275).

56 Por todos, Garrido (2007) p. 338.

57 En el mismo sentido Mañalich (2018b) p. 174. Sobre el fondo véase Maldonado (2015) pp. 216 y ss. El tratamiento de la "unidad de acción homogénea" está estrechamente vinculado al que se asigna al delito continuado, pues lo que se sostenga sobre uno impacta en la extensión de los casos que se reconocen en el ámbito del otro. Con detalle, CARuso (2018) p. 49 y ss. (quien además destaca la consideración de criterios comunes).

58 Por todos, CARUso (2018) p. 15

59 Los casos de ejecución iterativa, aluden a situaciones de "ejecución homogénea equivalente reiterada en tiempo próximo” (JeSCHECK y Weigend (2014) p. 1063; Mañalich (2005) p. 1031), mencionándose como ejemplos de estilo una paliza o un conjunto de insultos (Roxin (1997) p. 950). Por su parte, los casos de ejecución sucesiva se refieren a una "continuidad de actos que admite ser dividida en etapas" (MAÑAlich (2005) p. 1031; Roxin (1997) p. 953). En dicha denominación se incluyen los casos referidos a acciones prolongadas o plurales también denominados "delitos de acción múltiple homogénea", como la "pertenencia a una organización", la "falsificación de moneda" o el "suministro de información". RoXIN (1997) pp. 947-948; ORTIZ y ARÉVALO (2013) p. 320. Finalmente, están los casos de ejecución progresiva que son aquellos en los que una sucesión continua de actos "incrementa la gravedad objetiva del hecho" materializando una lesión que "va de menos a más”. Mir (2005) p. 627; CARUso (2018) pp. 27 y 28). Estos últimos admiten incluso que la "progresión" incluya ilícitos de diversa naturaleza (desde la injuria, a la amenaza, los golpes, la lesión física e inclusive la muerte) cuyo tratamiento debiese por ello corresponder a las esferas del concurso aparente de leyes penales (Etcheberry (1964) p. 20; Ortiz y Arévalo (2013) p. 359). En esta misma línea también cabe destacar que la jurisprudencia alemana reconoce una ejecución iterativa tratándose de casos en que se incurre en numerosas infracciones de tránsito en una misma persecución (Frister (2016) p. 674; RoXIN (1997) pp. 956-957). Para una visión crítica véase el propio Roxin (1997) en pp. 958-959; y Hilgendorf y Valerius (2017) p. 320. 
casos (todos) en los que resulta insuficiente constatar que un determinado supuesto de hecho satisface las correspondientes propiedades típicas para poder precisar si la ejecución es unitaria o plural, de forma que siempre se termina recurriendo a un criterio diverso o complementario, necesariamente externo o ajeno a dicha definición, a los efectos de "cuantificar”. En dicha tarea lo más usual es el recurso a factores naturalísticos (como la unidad del contexto fáctico, una cierta progresión en la lesión o la inmediatez o proximidad espacio-temporal, etc. ${ }^{60}$, propuesto incluso por autores que acertadamente los han descartado a nivel general ${ }^{61}$. Por sobre ellos, se recurre a la identificación de una intensión o vinculación subjetiva global ${ }^{62}$; a la constatación de uno o varios resultados típicos ${ }^{63}$, o a la lesividad concreta para un bien jurídico en particular ${ }^{64}$; en especial cuando se trata de un bien de carácter personalísimo ${ }^{65}$, con resultados que siempre se muestran insatisfactorios a nivel general. Lo único en que todas las propuestas coinciden es en la necesidad de contar con un criterio adicional que se identifica, en todos los casos, con la posibilidad de sostener una única acción (y, en ese sentido, una única ejecución o realización) que cuente como (única) ejemplificación de una determinada clase de acción ${ }^{66}$.

Al respecto creemos que las dificultades que ha enfrentado dicha tarea están estrechamente vinculadas a la pretensión de alcanzar criterios de carácter general para enfrentar estas problemáticas, pues se trata de una dinámica infructuosa a dichos efectos. La pretensión de alcanzar criterios comunes que tengan validez general pasa por alto que la determinación de una unidad (o pluralidad) depende inicialmente del tipo de objeto de que se trate, lo que demanda la consideración precisa de sus particularidades y de todas ellas ${ }^{67}$. Así, parece claro que no es lo mismo saber cuándo se ejecuta una lesión corporal o varias que cuando se lleva a cabo un hurto o una estafa o varias de ellas, pues en cada caso el análisis se debe fundar en elementos o particularidades diversas. De esta forma, lo primero a

60 Cury (2007) pp. 650, 651 y 663 y ss,; Cuerda (1997) pp. 348 y ss.; NovOA (2005) p. 222; RoXIN (1997) p. 947 (con matices). Véase también Cuello (1979) p. 56, quien califica este tipo de procedimientos como algo usual.

${ }^{61}$ Se suelen rechazar en Alemania y en España, Escuchuri (2004) p. 374. Crítico, con matices Nino (1972) p. 37; Ortiz y Arévalo (2013) p. 317;

62 Arce (1996) p. 45; Etcheberry (1964) p. 100; Jescheck y Weigend (2014) p. 1060; Welzel (1993) pp. 266 y 267; VÁsQUeZ (1996) pp. 218-219 (destacando que es dominante en USA y Puerto Rico)

63 Crítico Arce (1996) pp. 38-41; Caruso (2018) p. 19; Maurach et al. (1995) pp. 529-530; Zaffaroni Et. Al (2002) p. 855-857, en general, bajo el sencillo argumento de que una acción puede perfectamente provocar varios resultados.

64 Castelló (2000) pp. 47 y ss. Critico, Cid (1994) p. 46; Nino (1972) p. 51

65 Cárdenas (1973) p. 36; con matices (reconociendo algún grado de utilidad); Cury (2007) p. 651; Garrido (2007) p. 337; Politoff et al. (2003) p. 449; Escuchuri (2004) pp. 390-391; Frister (2016) p. 690; García (1995) p. 124 (en tanto no admiten graduación de la lesión). En el mismo sentido JaKOBS (1997) pp. 1081-1083).

66 ARCE (1996) p. 109; CARUSO (2018) p. 15. A este respecto se debe tener en cuenta que la posibilidad de afirmar una "unidad de delito" se basa en una doble relación de identidad como acertadamente ha destacado Mañalich en nuestro medio (Mañalich (2018 c) pp. 172-173; implícito Politofr et al. (2003) p. 441). En primer lugar, supone constatar la satisfacción de las propiedades de un único tipo de hecho punible y, en dicho caso, supone además verificar que sus exigencias solo se han satisfecho (en los hechos) en una única oportunidad, confirmando lo señalado. Sobre propuestas alternativas referidas a esta misma cuestión véase CARAMUTI (2018) pp. 45-47.

${ }^{67}$ Nino (1972) p. 36. 
tener en cuenta es que la operación a realizar debe tomar como base el contenido completo de cada tipo de delito en particular (de todas sus propiedades constitutivas) pues constituye una base (mínima) que en modo alguno se pude obviar, más allá de que en algunos casos se pueda requerir un ejercicio o complemento adicional y posterior ${ }^{68}$. Así se explica que las referencias propuestas en doctrina en torno a la lesividad del comportamiento (riesgo o lesión progresiva del bien jurídico), a las propiedades más significativas de la acción (en tanto modos de comisión específicos o alternativos) o a otros caracteres relativos a contenidos esenciales de la correspondiente infracción (como el resultado, el bien jurídico, su carácter personalísimo, y otras semejantes), parezcan del todo razonables de considerar, pues el problema que ofrece su consideración no dice relación en modo alguno con su pertinencia. En efecto, constituyen elementos de juicio tan correctos como insuficientes si se acude a ellos como criterios exclusivos, autónomos o individuales, pues de lo que se trata es de verificar la concurrencia de todas y cada una de ellas. Además, y por lo mismo, se trata de criterios o referentes que no ofrecen una utilidad general o común, pues no parece posible arribar a criterios únicos, uniformes o generales, teniendo en cuenta que cada delito ofrece elementos y propiedades definitorias que no tienen por qué ser coincidentes, ni comunes ${ }^{69}$.

Por sobre ello no hay que perder de vista que la operación a realizar con base en dicho contenido consiste en precisar cuándo un determinado ámbito del mundo (de la realidad) cuenta o puede contar como un caso o una concreta ejemplificación de las propiedades específicas que describen al correspondiente tipo de hecho punible de que se trate. Y cuando, a la inversa, dicho contexto refleja o da cuenta de una satisfacción plural de la totalidad de las propiedades correspondientes. De ahí que la naturaleza del problema a tratar diga relación con el campo de la subsunción y no -como suele proponerse- con una operación referida a la interpretación ${ }^{70}$, cuyo objetivo apunta a precisar una determinada instancia de realización o varias. Se trata por ello de un ejercicio eminentemente valorativo relativo a la dimensión intensional del respectivo delito ${ }^{71}$.

Con ello, se podrá también advertir que la operación que se demanda materializa un ejercicio que es propio de la llamada parte especial del derecho penal ${ }^{72}$, en cuanto responde al análisis propio de las particularidades que supone cada hipótesis punible en específico. Resulta por ello erróneo, y en buena medida "distractivo", referirlo a cuestiones circunscritas a la parte general, a la propia "teoría del delito" o a la "teoría del tipo", pues se trata de ámbitos relativos a cuestiones de carácter general y común. Tras ello resulta claro que la noción de

\footnotetext{
68 Arce Aggeo (1996) p. 109.

69 Así Castelló (2000) p. 40; con ejemplos relativos a la regulación del homicidio y del hurto.

70 Así, en el sentido objetado, Lifante (2015) p. 191, quien de una u otra forma identifica el problema como uno relativo a identificar cuál es la regulación jurídica aplicable a un determinado supuesto. Próximo CueLLo (1979) p. 48. Otra opinión en Caruso (2018) p. 15.

71 Mañalich (2014) p. 551. Por ello, no se trata solo de "clasificar", sino de "calificar" el hecho, que es lo propio de un proceso que supone la consideración y aplicación de una definición (conceptual). Al respecto, CASERO (2016) pp. 30 y 230 y ss. Sobre la dimensión intensional y extensional de un delito, a nivel general, véase (en términos descriptivos) García (1995) pp. 149 y 150; Mañalich (2018b) p. 185 y ss. Sobre la relación entre la noción de "realización de un supuesto" y su dimensión comunicativa véase FlETCHER (2008) p. 374.

72 Cuerda (1997) pp. 353-354; Escuchuri (2004) p. 396; Roxin (1997) pp. 948-949; Próximo ZafFaroni Et. $\mathrm{Al}(2002)$ p. 861.
} 
realización a la que hemos aludido da cuenta de un supuesto más amplio que las referencias alusivas a la idea de acción o hecho; siendo al mismo tiempo más específico ${ }^{73}$, tanto en lo referido a las propiedades o particularidades necesarias de advertir o constatar en los hechos, como en lo relativo a la multiplicidad de formas bajo las cuáles se pueden manifestar ${ }^{74}$.

Lo dicho resulta suficiente para dar cuenta del por qué creemos que en este plano tampoco cabe recurrir a una noción única o general de unidad de acción, en algo que sea diverso al contenido propio de lo que cuenta como delito en torno a cada figura punible ${ }^{75}$. Por sobre ello, creemos que resulta necesario compartir una única consideración general de carácter común a fin de dar cuenta más acabada de las referencias metodológicas necesarias de tener en cuenta en torno al caso-problema que nos ocupa en este apartado ${ }^{76}$. La tarea a realizar supone la concreción de un juicio valorativo de carácter específico, centrado en un supuesto de hecho particular y determinado (lo que realmente ocurrió). De esta forma, se deben descartar todo tipo de aproximaciones que supongan un fraccionamiento artificial de los mismos o razonamientos basados en lo que "pudiese haber ocurrido", lo que es usual. Así, no es relevante advertir que satisface las exigencias típicas el hecho de que el infractor introdujo su mano en la caja sustrayendo un fajo de billetes, si el caso plantea que lo hizo alrededor de treinta veces, pues con ello se pierde de vista que el problema radica en determinar concretamente si esta última descripción (completa) satisface una o varias veces, al supuesto en cuestión. Y lo propio sucede con quien propina una pluralidad de golpes en el rostro de la víctima, cuyo efecto acumulativo provoca una determinada lesión (caracterizada por una determinada gravedad o entidad). Fraccionar el hecho implica desconocer que las fases posibles de identificar en torno a un delito suelen carecer de relevancia autónoma en cuanto tales si forman parte de una ejecución más completa o acabada, pues en dichos supuestos no son "algo que ha sucedido", sino una mera suposición. De ahí que su conside-

\footnotetext{
73 La idea de "realización" no es extraña en el derecho penal. Se la utiliza acá, en torno a casos de unidad de acción homogénea (MAÑALICH (2018a) pp. 82, 94 y 95); para la identificación del sustrato de un delito (FERNÁNDEZ (2013) pp. 36, 37 y 44); en los actos anteriores y posteriores copenados (muy claro en NINO (1972) p. 61) y, con un sentido aún más amplio, en torno al concurso ideal (Frister (2016) pp. 671-672; Roxin (1997) pp. 969-970).

${ }^{74}$ La concreción que se demanda es doble pues, por un lado, se vincula al tipo de hecho punible de que se trate en específico y, por otro, alude a los caracteres concretos del supuesto de hecho en particular. Sobre esto último, CÁrdenas (1973) p. 85; FonteCilla (1956) p. 73.

75 Cobra sentido por ello (si bien resultan igualmente insuficientes y por la misma razón ya señalada) el recurso a planteamientos mixtos basados en una sumatoria de criterios complementarios, como en GARRIDO (2007) p. 337; Frister (2016) p. 672. Se refiere a ellos, con detalle, EsCUCHURI (2004) p. 389; CUERDA (1997) p. 346; SANZ (1986) pp. 130-131 y GARCía (1995) p. 121. En este sentido también caben referencias a la noción alemana de "unidad natural de acción", relativa a casos integrados por varias acciones que son reunidas por una apreciación interpretativa ("natural") fundada en la "normal concepción de la vida". Al respecto, RoxiN (1997) p. 945 y ss. y, especialmente, p. 950; Frister (2016) p. 669. No se puede sin embargo obviar que su uso se critica profusamente por su indeterminación, arbitrariedad o vaguedad, como destaca JESCHECK y WEIGend (2014) p. 1061; JaKobs (1997) pp. 1090-1091; STRATENWERTh (2005) p. 537 y ZaFFaroni Et. Al (2002) pp. 857-858.

76 Por razones de espacio, y en atención a que lo dicho da cuenta de lo necesario en torno al objeto de análisis específico que nos hemos propuesto para ser desarrollado en el presente trabajo, es que no nos resulta posible extendernos en mayor medida en relación a la forma como se resuelven o pueden resolver los diversos casos problemáticos que se produzcan en particular.
} 
ración y descripción suela estar condicionada a una efectiva ejecución imperfecta ${ }^{77}$. Por esta razón el ejercicio adopta la estructura de un concurso aparente de leyes penales, donde las opciones consisten en el reconocimiento de un concurso real, por un lado, o la afirmación de una única ejecución, por el otro $^{78}$, a resolver con miras a determinar cuál modalidad capta en mejor manera, y de forma íntegra, el desvalor del hecho ${ }^{79}$.

\section{UNIDAD DE HECHO EN EL CONCURSO IDEAL}

Finalmente, corresponde hacernos cargo de la noción de unidad de acción o de hecho en la distinción entre concurso real e ideal, ámbito en el que, por definición y a diferencia de los casos anteriormente analizados, la noción no juega un papel relevante para la cuantificación de hechos punibles ${ }^{80}$. Ello es así, pues todo concurso de delitos se define por la concurrencia plural de normas incriminatorias en un mismo contexto de juzgamiento, de forma que resulta irrelevante el modo, contexto o relación bajo la cual hayan sido llevadas a cabo. El concurso ideal es un concurso de delitos y supone por ello, por definición, dicha pluralidad. Por ello, se debe afirmar un concurso equivalente en unidad de acción o de hecho (concurso ideal) o en caso de pluralidad (concurso real), perspectiva que demuestra su sentido tras afirmaciones como la siguiente: matar a muchos mediante una metralla

77 Escuchuri (2004) pp. 302-303; García (1995) p. 131; Jakobs (1997) p. 1059; Mañalich (2005) p. 1046; Maurach et al. (1995) p. 584; Ortiz y Arévalo (2013) p. 358. Por ello carece de sentido tratar estos casos como "actos anteriores copenados" como destaca, por todos, Roxin (1997) p. 955, a menos que se trate de tentativas "fallidas" (MATus (2002) p. 34. Matus (2005) p. 487). Este ejemplo permite ratificar la relevancia de la aproximación interpretativa "de parte especial", mecánica a la que varios autores recurren, especialmente, para el análisis de los actos anteriores y posteriores copenados. Al respecto véase ETCHeberry (1964) pp. 38 y 39 ; Nino (1972) p. 62.

78 En el mismo sentido Frister (2016) p. 690 (quien alude al concurso ideal aparente homogéneo). Asimismo, véase MALdonado (2015) pp. 216-221, en relación a lo que califica como el reconocimiento auténtico de un delito continuado.

$79 \mathrm{Al}$ respecto, Ortiz y ArÉvalo (2013) p. 334. Lo dicho coincide con el objetivo general que se asigna a toda la teoría concursal, asociado el principio ne bis in idem y del mandato de exhaustividad (mal reflejado en la alusión al principio "qua delicta tot poenae"). Al respecto ArCE (1996) pp. 22 y ss.; Cid (1994) p. 53; ETCHEBerRY (1997) p. 109; Escuchuri (2004) pp. 26, 65 y, especialmente, 433 y ss.; Muñoz (1986) p. 343; Mañalich (2005) p. 1025; NovoA (2005) p. 220. El punto no alude necesariamente a la identificación de una mayor o menor pena, sino a una que se ajuste en términos proporcionales a las valoraciones que el propio legislador sugiere en las definiciones generales sobre pena y en la precisa asignación de los correspondientes marcos penales. Sobre ello véase Maldonado (2016b) pp. 583 y ss. Sobre lo impropio de recurrir a la "mayor pena", en general, Frister (2016) p. 681; Matus (2005) p. 476; Pessoa (2018) p. 85; Zaffaroni Et. Al (2002) p. 867; EtchebeRRY (1964) pp. 50 y 93, quien además cita a dichos efectos al art. 23 del Código Civil chileno). Véase también Alonso (2018) p. 184 en relación a cualquier conflicto de normas. Sobre el criterio opuesto -la menor pena o recurso "pro reo"- véase asimismo AlOnso (2018) pp. 144-145. Lo dicho se ratifica tras el reconocimiento de que es posible atribuir preferencia a una regla con menos pena, como en el caso de delitos privilegiados (DIAS (2013), p. 65; Etcheberry (1997) p. 124; Fontecilla (1956) p. 99; Mañalich (2005) pp. 1045, 1172-1173; Novoa (2005) p. 254; Ortiz y Arévalo (2013) p. 357).

${ }^{80}$ Mañalich (2005) pp. 1027 y 1034. 
o hacerlo mediante disparos individuales es, a fin de cuentas, lo mismo, aun y cuando se realice en contextos próximos o espaciados ${ }^{81}$.

Si esto es así, la distinción se justificaría si ofrece una relevancia diversa, descartada de plano la opción de definir la unidad de acción o hecho con base en el contenido del delito (pues, como ya dijimos, habrá tantos como delitos concurrentes) ${ }^{82}$. Bajo este supuesto hay que tener en cuenta que la mayoría de los regímenes establecen una regla comparativamente atenuada para el tratamiento del concurso ideal ${ }^{83}$ de forma que la tarea del interprete consiste en identificar el criterio que explique dicha determinación (con independencia de su suficiencia o valoración político criminal ${ }^{84}$. Desde esta perspectiva la tarea a desarrollar se vincula a interpretar dicha decisión regulativa, pues, como cualquiera, demanda un ejercicio hermenéutico ${ }^{85}$. Resulta por ello idóneo recurrir primariamente al sentido natural (genérico) de la expresión (acción o hecho) que es donde se ha situado en general las propuestas de solución (por sobre la errónea utilización, más o menos precisa, de la misma noción de acción que es propia de la definición de lo ilícito). A este respecto los criterios conocidos recurren a tres órdenes de consideraciones: por un lado, una pluralidad de variantes asociadas al contexto y a razones naturalísticas tributarias de la perspectiva espacio-temporal (como el contexto, la unidad de situación o el carácter ininterrumpido de la ejecución) ${ }^{86}$; por otro las referidas a un criterio externo o construido, como sucede con la identificación de una unidad tras un efecto tangible (aproximación objetiva ${ }^{87}$ ) o una determinada dirección de la voluntad (aproximación subjetiva ${ }^{88}$ ); otros, finalmente, procuran delimitar la ejecución unitaria bajo la idea de que no ha sido para el autor resolver la ejecución de los delitos en forma separada (evitabilidad conjunta ${ }^{89}$ y concurrencia necesaria

\footnotetext{
81 Véase Caruso (2018) p. 18; Rolg (2011) pp. 120 y ss., en el sentido del ejemplo. Sobre esta base la consideración de los delitos concurrentes no plantea un supuesto que habilite a considerar una regla penológica diferenciada. Por ello, parte de la doctrina sostiene que ni la distinción ni el tratamiento diferenciado se justifican. Garrido (2007) p. 350; Matus (2002), p. 27; Matus (2005) pp. 469; SuÁrez (2001) pp. 51 y ss. y p. 147 y Escuchuri (2004) pp. 90 y 91 (con especial de referencia al medio español). En Alemania, Frister (2016) p. 667 (quien lo califica como "un privilegio injustificado").

82 Ver nota No 6.

83 Como excepción se menciona Estados Unidos y el abandono de la distinción en Francia, Portugal, Austria y Suiza. Mañalich (2005) p. 1150; Suárez (2001) p. 53; Stratenwerth (2005) p. 549; Sanz (1986) pp. 57 y ss.

${ }^{84}$ No basta con identificar una forma de sostener la unidad de acción o de hecho pues se requiere además de una conceptualización idónea. Constituyen por ello dos cuestiones diversas pero íntimamente relacionadas pues una determinada forma de entender la unidad de hecho no presupone necesariamente una razón que justifique un trato penológico diferente. Otra cosa es que se pueda afirmar que se trata de una razón suficiente o de peso para justificarlo o de valorar la conveniencia de la decisión legislativa. Sobre el habitual uso de esto último como distorsión en la actividad hermenéutica (especialmente en este ámbito) véase MALdONADo (2016b) pp. 557 a 561.

85 Mañalich (2005) p. 1192.

86 Novoa (2005) pp. 222-223; Politoff et al. (2003) p. 445.

$87 \mathrm{Al}$ respecto, a nivel general, véase VAN WeEZEL (2020) pp. 9, 10 y, especialmente, 11 y 12.

88 Arce (1996) p. 45; Escuchuri (2004); Stratenwerth (2005) p. 537 y, en nuestro medio, Etcheberry (1964) p. 100; GARRIDO (2007) p. 337. Cita de otros autores de referencia en SuÁrEZ (2001) p. 76. Constituye el criterio dominante en el siglo XIX y hasta la mitad del XX como destaca Alvarez (2008) p. 66.

89 Mañalich (2018b) pp. 188; Mañalich (2018a) p. 85. Crítica en Maurach et al. (1995) p. 528.
} 
o indivisible ${ }^{90}$ ). En los primeros casos, se suelen expresar razones asociadas a la constatación de una vulneración al ne bis in idem, mientras que en el segundo, el criterio se asocia preferentemente al reproche de culpabilidad, en atención a que lo inevitable de la ejecución conjunta o necesaria supondría un déficit en la voluntariedad del acto ${ }^{91}$.

Cada una de estos planteamientos ha sido objeto de observaciones y críticas -algunas bastante profusas- ofreciendo un panorama de conjunto poco alentador ${ }^{92}$. En cuando a la unidad de contexto lo primero es reiterar que se trata de un criterio de aproximación que, por definición, no resulta idóneo para ofrecer criterios o contenidos útiles para identificar una unidad (de cualquier clase) ${ }^{93}$. Por sobre ello, también se debe descartar la posibilidad de que ofrezca sustento para sostener un bis in idem, bajo la idea de que nadie podría ser sancionado dos veces por el mismo "hecho" ${ }^{94}$. Lo relevante es que dicha afirmación no se sostiene, por la sencilla razón de que no es posible advertir una doble valoración con base en la consideración exclusiva del contexto material, naturalístico o extensional que ofrece la ejecución de un delito pues, por definición, se trata de una restricción que toma como objeto de referencia al ámbito valorativo ${ }^{95}$. Por esta misma razón se debe también descartar toda otra noción que carezca de una dimensión de sentido como sucede paradigmáticamente con la alusión a la provocación de un "efecto" o resultado, si se la pretende ocupar en forma idónea (lo que supone un contenido diverso al uso que ofrece dicho término en la teoría del delito $)^{96}$. También se suele criticar el recurso a una finalidad común, en tanto no hace más que replicar el caso de que trata el llamado concurso medial, resultando absurdo

\footnotetext{
90 Labatut (1983) Tomo I, p. 173; Muñoz (1986) p. 359 y 362; Ortiz y Arévalo (2013) pp. 349, 350 y 352. Asimismo, véase CÁRdenAs (1973) pp. 79 y 80 (en cita a la opinión propuesta sobre esta cuestión en particular por parte de la comisión chilena que intervino en la preparación del Código Penal tipo para Latinoamérica). Constituye en nuestro medio la opinión dominante por una consideración histórica, vinculada a la interpretación propuesta por Pacheco sobre el Código Penal español de 1848, PACHeco (1888) pp. 421 a 423 . Lo constata Etcheberry (1997) p. 120; Garrido (2007) p. 350; Labatut (1983) p. 173.

91 Por todos, Ortiz y Arévalo (2013) p. 343.

92 Con detalle véase Maldonado (2020).

93 Ver nota No 11.

94 En este sentido Días (2013) p. 65, con amplia cita de autores de referencia (sin compartir el criterio). Asimismo, a los mismos efectos, véase SANZ (2012) p. 44 y MATus (2005) p. 467. Entre los autores aludidos se cuenta reiteradamente a Mir, Cuerda y Puppe. Véase también Ossandón (2018) p. 965, reconoce un "cierto efecto parcial del principio" fundado en la "cierta identidad" que ofrece el hecho. En un sentido similar, sostuve un criterio equivalente en MALDONADO (2014) pp. 96, que hoy he abandonado.

95 Lo dicho es fundamental pues la prohibición no proscribe la doble valoración, ni la sanción múltiple, sino la repetición de la misma valoración. Nada obsta a que un hecho sea regulado y sancionado con un conjunto de reacciones, sea que se impongan en una misma disposición (como en las penas copulativas) o en varias. Al respecto Hernández (2014) p. 571; Maldonado (2016b), pp. 579 a 581; Mañalich (2014) p. 559; Ossandón (2018) pp. 963, 964 y 986). Por ello sí lo relevante es la dimensión de sentido habrá que comparar las propiedades que definen las respectivas infracciones (MañAlich (2018b) pp. 198 y ss.; Matus (2005) p. 468), a fin de sostener que se repite la misma valoración (García (1995) pp. 101 y 102; Mañalich (2005) p. 1026), lo que supone operar en torno a la dimensión intensional del supuesto (CASERo (2016) pp. 30 y 230 y ss.; GarCía (1995) pp. 234 a 239; Mañalich (2018b) pp. 204 a 206; Mañalich (2014) p. 551; Ossandón (2018) pp. 966 y 967; RatTi (2013) p. 243).

96 En el sentido objetado, parcialmente, MañAlich (2018 a), pp. 83 y 84 (en cuando lo refiere a una definición "débilmente extensional"). Asimismo, sobre el fondo, véase Van Weezel (2020), pp. 11 y 12.
} 
que el legislador se haya ocupado de regular el mismo instituto en dos ocasiones diversas, y en forma tan próxima, y con el mismo efecto.

Por su parte, el recurso a la imposibilidad de ejecución separada no parece realmente orientado a favorecer la identificación de una sola acción o hecho, a pesar de que resulta indiscutiblemente idóneo para ello. Lo relevante radica en que pone sobre la mesa la posibilidad de considerar que el carácter involuntario de dicha ejecución conjunta puede ofrecer un criterio idóneo para justificar la categoría y -en especial- el tratamiento penológico (privilegiado) que se le asigna ${ }^{97}$. No obstante, no parece que realmente aporte en esa dirección ${ }^{98}$. Quien se enfrenta a la ejecución conjunta de dos delitos ejecuta ambos, resuelve ambos y decide ambos, sin que dichos contenidos se presenten en forma diversa en relación a los casos de ejecución separada. Y el que no haya podido evitar su realización conjunta no es algo que modifique dicha argumentación ${ }^{99}$.

En mi caso creo que la aproximación natural a la lingüística siempre ofrecerá resultados parciales conclusión que habilita a recurrir al ámbito de la teleología y a los fundamentos asociados a la génesis del precepto. En dicho plano creo que se puede identificar como razón el que los casos de ejecución "diferenciada" o "independiente" (esto es, los que pueden ser calificados como concurso real) se dejan interpretar como casos de reiteración ${ }^{100}$, de forma que admiten el reconocimiento de los significados y efectos asignados a este tipo de supuestos (ej. rebeldía) ${ }^{101}$, en los regímenes que lo reconocen ${ }^{102}$. La unidad de hecho, a este respecto, se puede configurar por ello en torno al fragmento de la realidad que pueda ser indicado como continente de una ejecución delictiva, en tanto dicha extensión da cuenta de una única instancia de realización que puede ser interpretada o leída como infidelidad o afrenta al derecho ${ }^{103}$. Así se explica también la necesidad de extender dicho supuesto al concurso medial, en tanto dicha conexión funcional permite interpretarlo como parte de

\footnotetext{
97 En ese sentido, concretamente, MaURach et al. (1995) p. 582.

98 Así se reconoce por Mañalich (2018a) p. 85.

99 El mismo razonamiento se replica en torno a los casos que se tratan bajo el rótulo del llamado dolo de las consecuencias necesarias o seguras, a cuyo respecto la doctrina uniformemente acepta la atribución completa (a título de dolo). Sobre ello, por todos, CuRY (2007) pp. 316 y 317.

100 Ferrini (2017) p. 134. Maldonado (2016b) pp. 115 y ss.

101 Véase Feuerbach (1989) p. 123, en alusión específica a los “crímenes reiterados".

102 La verdad es que los diversos sistemas penales reconocen y han reconocido siempre efectos asociados al dato que aporta la recaída o reiteración, en una constelación de supuestos que excede con mucho a la agravante de reincidencia. Con detalle, Maldonado Fuentes (2016a) pp. 90-91 y 109. Asimismo, debe tenerse en cuenta la amplia aceptación de reglas especiales aplicables al "primerizo", lo que, de suyo, supone la legitimación de un tratamiento diferencial con el reiterante. Maldonado Fuentes (2016a) pp. 104 y ss.

103 ARCE (1996) pp. 55 a 57, en referencia a Carrara. En un sentido equivalente Bustos (1962) pp. 64 y 66; Frister (2016) p. 668; Lurati (2018) p. 118 (se trata de "una única culpabilidad"). A nivel general Roig (2011) pp. 353 a 355 (con cita de autores de referencia). En un sentido equivalente Groizard (citado en SANZ (1986) p. 180) y Fontecilla (1956) pp. 78 y 79). Lo dicho constituye el procedente directo de la llamada "teoría de la unidad", dominante en Alemania en el Siglo XIX, y que describe el concurso ideal como un caso de "unidad de delito" que, a pesar de la unidad de acción, amerita una pluralidad de calificaciones jurídicas. MAURACH et al. (1995) p. 520.
} 
la (misma) ejecución ${ }^{104}$. De esta forma, la identificación del concurso ideal (esto es, de un concurso llevado a cabo en unidad de hecho) solo busca reconocer que el legislador pretende ser menos severo con quien no ha reiterado en la comisión del delito, pretensión que subyace a la generalización de la regla de acumulación material de infracciones. Lo dicho se respalda concretamente en el contexto histórico bajo el cual se origina "la moderna teoría concursal", y que remite a "los prácticos", Koch, Becker y -fundamental- Feuerbach, en quien se advierte aun de forma más nítida ${ }^{105}$.

Por ello, en términos sencillos, lo que vale como unidad de hecho a este respecto corresponde al sustrato empírico que se extiende desde la ejecución de los actos que den inicio a la correspondiente y específica tentativa hasta, al menos, la satisfacción del último de aquellos que valen como actos de ejecución (propia) ${ }^{106}$.

\section{COROLARIO FINAL}

Finalmente conviene expresar un breve comentario sobre el rol de la unidad de acción o hecho como presupuesto de la teoría concursal en general. La idea de concurrencia encuentra su referente propio en el proceso, no en el delito o en una determinada acción o hecho en particular, diverso del que sugiera el contexto procesal ${ }^{107}$. Es a dicho respecto que concurren los delitos. Con ello, el caso que le da sentido a la categoría no se refiere a toda situación en la que una misma persona ha cometido varios delitos (a pesar de que "concurren", a su respecto) o que deba ser sancionada por varios de ellos (en cuyo caso hay más bien concurrencia de penas, a su respecto), sino solo a aquellas situaciones en las que dichas definiciones deben tener lugar en el contenido de un mismo acto de adjudicación (una misma sentencia). Así se explica por qué las reglas concursales previstas en el derecho positivo (en general escasas o parcas) suelan ubicarse en torno a la sistemática de la determinación de la pena pues, a fin de cuentas, en todos estos casos, se trata de determinar cómo se le debe sancionar al infractor de varios delitos ${ }^{108}$. Lo dicho se vincula estrechamente a

${ }_{104}$ De ahí que sea correcta la postura dominante que los identifica como casos de concurso real. Por todos, ORtiz y Arévalo (2013) p. 334; Politoff et al. (2003) p. 444.

105 Cárdenas (1973) pp. 11 y 12; Arce (1996) p. 35; Escuchuri (2004) p. 207; Sanz (1986) pp. 39 y ss., Mezger (1958) p. 331. Con mucho mayor detalle Maldonado, 2020.

106 StratenWerth (2005) p. 550; SAnZ (1986) p. 152. Con ello se deben rechazar aquellas posturas que llegan a situar el límite en torno a las manifestaciones de lo que cuenta como agotamiento del delito, como en FRISTER (2016) pp. 671 y 672 o en Roxin (1997) pp. 969 y 970. Asimismo, en torno a aquellos casos en que uno de los delitos supone la constatación de una tendencia interna trascendente que luego se realiza en el otro delito (Roxin (1997) p. 970). Asimismo, tampoco parece acertada la doctrina -dominante en Alemania- que rechaza unidad de hecho o acción en casos de superposición parcial en tentativa (Roxin (1997) pp. 970 y 971) y que también encuentra adherentes en España (como Vives (1981) p. 17).

107 Maurach et al. (1995) p. 580; Sanz (2012) p. 7. Suárez (2001) pp. 85 y ss.; Vives (1981) p. 15, Próximo, Mañalich (2005) p. 1104. Lo relevante es la posibilidad de juzgamiento conjunto, en términos que lleven a sancionarlos en una misma sentencia (CARAMUTI (2018) p. 210; EsCUCHURI (2004) pp. 57-58; RoXIN (1997) pp. 941 y 981; Stratenwerth (2005) p. 534). De ahí el nexo con la determinación de la pena (Dias (2013) p. 62; Fontecilla (1956) p. 94; Frister (2016) p. 663; Mañalich (2004) p. 484). El punto se destaca en términos históricos, ya en Roma. Al respecto, FERrini (2017) pp. 136-137.

108 Fontecilla (1956) p. 94; Dias (2013) p. 62; Mañalich (2004) p. 484; Vives (1981) p. 41. 
la atribución de un sentido valorativo al acto de adjudicación. La sentencia no es un acto neutro que simplemente replique el mandato de normas de sanción individuales. La condena constituye un acto significativo que se expresa en un régimen de padecimiento que se estructura a partir del contenido de las reglas de sanción, pero que no se identifica de forma necesaria con estas.

\section{BIBLIOGRAFÍA CITADA}

Alchourron, Carlos y Bulygin, Eugenio (2006): Introducción a la metodología de las ciencias jurídicas y sociales (Buenos Aires, Edit. Astrea).

Alonso, Juan Pablo (2018): Principios jurídicos implícitos (Barcelona, Edit. Marcial Pons).

Alvarez Pozo, María de la Palma (2008): "La génesis de la teoría del Concurso de delitos en el ordenamiento jurídico español”, Cuadernos de Política Criminal, No 94: pp. 33-70.

Arce Aggeo, Miguel Ángel (1996). Concurso de delitos en materia penal (Buenos Aires: Editorial Universidad).

Bulygin, Eugenio (1991): “Dogmática jurídica y sistematización del derecho” en AlCHOURron y Bulygin, Análisis lógico y Derecho (Madrid, Edit. Centro de Estudios Constitucionales), pp. 465-484.

Bustamante, Thomas (2010): "Conflictos normativos y decisiones contra legem: una explicación de la derrotabilidad normativa a partir de la distinción entre reglas y principios”, Doxa, Cuadernos de Filosofía del Derecho, No 33: pp. 79-108.

Bustos Ramírez, Juan (1962): Concurso ideal de delitos (Santiago de Chile: Editorial Universitaria, Universidad de Chile).

Caramuti, Carlos (2018): Concurso de delitos, $3^{\mathrm{a}} \mathrm{ed}$. (Buenos Aires: Edit. Hammurabi).

Cárdenas, Raúl (1973): El concurso ideal para el Código Penal tipo para la América Latina (México, Ediciones Botas).

Caruso Fontan, María Viviana (2018): Unidad de acción y delito continuado (Valencia, Tirant lo Blanch).

CASERo BARRón, Ramón (2016): Interpretación de la norma jurídica: Lógica, teleológica y analógica (Madrid, Edit. Thomson Reuters Aranzadi).

CAstelló Nicas, Nuria (2000): El concurso de normas penales (Granada, Comares).

Cid Moliné, José (1994): "Notas acerca de las definiciones dogmáticas de concurso de delitos", Anuario de Derecho Penal y Ciencias Penales, No 47: pp. 29-64.

Cuello Contreras, Joaquín (1979): "La frontera entre el concurso de leyes y el concurso ideal de delitos: la función de la normativa concursal (I)", Anuario de Derecho Penal y Ciencias penales, vol. 32, No 1: pp. 45-92.

Cuerda Riezu, Antonio (1997): "La unidad de delito en la jurisprudencia del TS”, en SiLva SÁnchez (edit.), Política criminal y nuevo derecho penal, Libro homenaje a Roxin (Barcelona, Bosch), pp. 341-354.

Cury Urzúa, Enrique (2007): Derecho Penal. Parte General (Santiago, Universidad Católica de Chile).

Días, Horacio (2013): "De cómo contar los delitos", en VV.AA, Anuario de Derecho Penal 2012 (Buenos Aires, AD-HOC), pp. 61-69. 
Diez Ausin, Francisco (1994): "Conflictos normativos y análisis lógico del derecho", Anuario de Filosofía del Derecho, Vol. IX: pp. 393-406.

EsCuChurI, Estrella (2004): Teoría del concurso de leyes y de delitos: bases para una revisión crítica (Granada, Comares).

Etcheberry, Alfredo (1997): Derecho Penal, $3^{\circ}$ edición revisada y actualizada, Tomo II (Santiago, Editorial Jurídica de Chile).

EtCheberry, Alfredo (1964): El concurso aparente de leyes penales (Santiago, Editorial Jurídica de Chile).

Fernandez, Gonzalo (2013): "Criterio de determinación de la unidad de hecho en el concurso de delitos", en VV.AA., Anuario de Derecho Penal 2012 (Buenos Aires, ADHOC), pp. 25 a 46.

FERRER, Jordi y RodríGUEZ, Jorge Luis (2011): Jerarquías normativas y dinámica de los sistemas Jurídicos (Barcelona, Marcial Pons).

Ferrini, Contardo (2017). Derecho penal romano (Barcelona, Marcial Pons).

Feuerbach, Paul Anselm (1989): Tratado de Derecho Penal, común vigente en Alemania, trad. de la $14^{\mathrm{a}} \mathrm{ed}$. Alemana (Buenos Aires, Hammurabi).

Fletcher, George (2008): Gramática del Derecho Penal (Buenos Aires, Hammurabi).

Fontecilla Riquelme, Rafael (1956): Concursos de delincuentes, de delitos y de leyes penales y sus principales problemas jurídicos (Santiago, Editorial jurídica de Chile).

Frister, Helmut (2016): Derecho Penal. Parte General, trad. 4a ed. Alemana (Buenos Aires, Hammurabi).

García Alberó, Ramón (1995): Non bis in idem material y concurso de leyes penales (Barcelona, Cedecs).

Garrido Montt, Mario (2007): Derecho Penal. Parte General, $4^{\circ}$ ed. (Santiago, Edit. Jurídica de Chile).

González Lagier, Daniel (2015): Conceptos básicos del derecho (Barcelona, Marcial Pons).

Guastini, Ricardo (2016): La sintaxis del derecho (Barcelona, Edit. Marcial Pons).

Guastini, Ricardo (2015): "Interpretación y construcción jurídica", Isonomía, No 43: pp. 11-48.

Guastini, Ricardo (2011): “Contribución a la teoría del ordenamiento jurídico”, en Ferrer, et al. (coords.), Realismo jurídico genovés (Madrid, Marcial Pons), pp. 81-116.

Hernández Basualto, Héctor (2014): "Actividad administrativa, procedimiento sancionatorio-administrativo y proceso penal: algunas necesidades de coordinación legal", en Arancibia Mattar, Et. Al (coords.), Sanciones Administrativas. X Jornadas de Derecho Administrativo (Santiago, Thomson Reuters), pp. 567-586.

Hilgendorf y Valerius (2017): Derecho Penal. Parte general, trad. 2a ed. Alemana (Buenos Aires, Ad-Hoc).

Huerta Ochoa, Carla (2003): Conflictos Normativos (México, Ed. Universidad Nacional Autónoma de México).

ItURRAlde Sesma, Victoria (1987): "Una aproximación al tema de las antinomias normativas: problemas relativos a la identificación de las mismas", Anuario de Filosofía del Derecho, No 4: pp. 331-354. 
Jakobs, Günther (1997). Derecho Penal. Parte General. Fundamentos y Teoría de la Imputación, 2a Edición corregida (Madrid, Marcial Pons).

Jescheck, Hans Heinrich y Weigend, Thomas (2014): Tratado de Derecho Penal. Parte general, trad. $5^{a}$ ed. (Lima, Edit. Instituto Pacífico).

Labatut Glena, Gustavo (1983): Derecho Penal, Tomo II, 7a ed. (Santiago, Editorial Jurídica de Chile).

Lifante Vidal, Isabel (2015): "Interpretación y aplicación del derecho", en GonZÁlez LAGIER (coord.), Conceptos básicos del derecho (Barcelona, Marcial Pons), pp. 185-201.

Lurati, Carina (2018): El sistema de pena única en el Código Penal Argentino, 2a ed. (Buenos Aires, Rubinzal-Culzoni).

Maldonado Fuentes, Francisco (2020): Unidad de hecho en el concurso ideal (inédito, aprobado para publicación en Revista Ius et Praxis).

Maldonado Fuentes, Francisco (2016a): "Reiteración y reincidencia: conceptos y fundamento", en del mismo (coord.), Reincidencia y concurso de delitos (Montevideo / Buenos Aires, BdeF), pp. 89-145.

Maldonado Fuentes, Francisco (2016b): "Reiteración y concurso de delitos. Consideraciones sobre el artículo 351 del Código Procesal Penal a partir de la teoría general del concurso de delitos en el derecho chileno", en CÁrdenas, et al. (Coords.), El Derecho Penal como teoría y como práctica. Libro Homenaje al Prof. Alfredo Etcheberry (Santiago, Thomson Reuters), pp. 549-607.

Maldonado Fuentes, Francisco (2015): "Delito continuado y concurso de delitos", Revista de Derecho de la Universidad Austral de Valdivia, Vol. XXVIII, No 2: pp. 193-226.

Maldonado Fuentes, Francisco (2014): "Consideraciones sobre la producción de resultados de riesgo general o de una multiplicidad de resultados lesivos a partir de la ejecución de una sola conducta delictiva en el derecho chileno. A propósito del desempeño en el tráfico rodado", Revista Doctrina y Jurisprudencia Penal (Santiago, Thomson Reuters), pp. 77-100.

Mañalich Raffo, Juan Pablo (2018a) "El principio ne bis in ídem como estándar de derecho sancionatorio, en el derecho penal chileno", en, del mismo, Estudios sobre la fundamentación y determinación de la pena, Santiago de Chile: Edit. Thomson Reuters, pp. 67-103.

Mañalich Raffo, Juan Pablo (2018b), "El concurso aparente como herramienta de cuantificación penológica de hechos punibles", en, del mismo, Estudios sobre la fundamentación y determinación de la pena, Santiago de Chile: Edit. Thomson Reuters, pp. 171-211.

Mañalich Raffo, Juan Pablo (2014): "El principio ne bis in idem frente a la superposición del derecho penal y el derecho administrativo sancionatorio", Revista Política criminal, Vol. 9, No 18: pp. 543-563.

Mañalich Raffo, Juan Pablo (2005): "El concurso de delitos: bases para su reconstrucción en el derecho penal de Puerto Rico", Revista Jurídica de la Universidad de Puerto Rico, No 74, pp. 1021-1211.

Mañalich Raffo, Juan Pablo (2004). "Asperación de la pena bajo el régimen del concurso real”, Revista de Derecho de la Universidad Adolfo Ibáñez, No 1: pp. 246-248. 
Martínez Arrieta, Andrés (1993): "La determinación judicial de la pena en el código penal español", en V.V.A.A: Política criminal y Reforma penal: Homenaje a la memoria del prof. Dr. D. Juan del Rosal (Madrid, Edit. Edersa), pp. 811-831.

Matus Acuña, Jean Pierre (2005): "Los criterios de distinción entre el concurso de leyes y las restantes figuras concursales en el Código Penal español de 1995, Anuario de Derecho Penal y Ciencias Penales, vol. 58, No 2: pp. 463-494.

Matus Acuña, Jean Pierre (2002): "La teoría del concurso aparente de leyes penales el resurgimiento de lay en principio desplazada", Revista de la Universidad Católica del Norte, No 9: pp. 27-68.

Matus Acuña, Jean Pierre (2000): "La teoría del concurso (aparente) de leyes en la dogmática alemana, desde sus orígenes hasta el presente (primera parte)", Revista Ius et Praxis, Vol 6, No 2: pp. 195-371.

Matus Acuña, Jean Pierre (1999): "Aportando a la reforma penal chilena. Algunos problemas derivados de la técnica legislativa en la construcción de delitos impropios: el error y el concurso", Ius et Praxis, Vol. 5, No 2: pp. 63-113.

Maurach, Reinhart, Gössel, Karl Heinz, Zipf, Heinz (1995): Derecho Penal. Parte General (trad. Bofill Genzsch), Tomo II (Buenos Aires, Astrea).

Mezger, Edmundo (1958): Derecho Penal. Libro de Estudio, Parte general (Buenos Aires, Editorial Bibliografía Argentina).

Mir Puig, Santiago (2005): Derecho Penal. Parte General (Barcelona, Edit. Reppertor).

Moreso, José Juan (2010): "Condicionalidad, derrotabilidad y conflicto entre normas", en Ortega Gomero (Edit.): Interpretación y razonamiento jurídico, Volumen II (Lima, Ara Editores), pp. 109-132.

Muñoz Horment, Humberto (1986): "Contribución al estudio de la teoría de los concursos de delitos", Revista Chilena de Derecho, Vol. 13: pp. 335-381.

Navarro, Pablo / Moreso, José Juan (1996): "Aplicabilidad y eficacia de las normas jurídicas", Isonomía, No 5: pp. 125-139.

Nino, Carlos Santiago (1995): Introducción al análisis del Derecho, 2a edición (Buenos Aires, Edit. Astrea).

Nino, Carlos Santiago (1972): El concurso en el derecho penal: Criterios para clasificar los casos de varios hechos o de varias normas en la calificación penal de una conducta (Buenos Aires, Astrea).

Novoa Monreal, Eduardo (2005): Curso de Derecho Penal chileno, 3a Edición (Santiago, Edit. Jurídica de Chile).

Ortiz Quiroga, Luis y Arévalo, Javier (2013): Las Consecuencias jurídicas del delito (Santiago, Editorial Jurídica de Chile).

Ossandon W., Magdalena (2018): "El legislador y el Principio ne bis in ídem”, Revista Política criminal, Vol. 13, No 26: pp. 952-1002.

PAcheCo, Joaquín Francisco (1888): El Código penal concordado y comentado, $6^{a}$ edición (Madrid, Edit. Imprenta y Fundición de Manuel Tello).

Palma Herrera, José Manuel (2004). Los actos copenados (Madrid, Dykinson).

Peñaranda Ramos, Enrique (1991): Concurso de leyes, error y participación en el delito (Madrid, Civitas). 
Pérez Bermejo, Juan Manuel (2009): "Normas jurídicas, conflictos y derrotas: entre normas ad-hoc y sub specie aeternitatis", Revista Analisi e Dirito: pp. 11-60.

Pessoa, Nelson (2018): Teoría de la unidad y pluralidad delictiva. Estudio del múltiple encuadre típico (Buenos Aires, Rubinzal-Culzoni).

Politoff, Sergio y Matus, Jean Pierre y Ramírez, Cecilia (2003): Lecciones de Derecho Penal. Parte General (Santiago, Editorial Jurídica de Chile).

Prambs, Claudio (2010): “¿Es posible sancionar las lesiones y el homicidio en concurso ideal?", Revista de Derecho de la Pontificia Universidad Católica de Valparaiso, No XXXIV, 1 sem.: pp. 459-474.

RatTI, Giovani (2013): El gobierno de las normas (Barcelona, Editorial Marcial Pons).

Rettig, Mauricio (2017): Derecho Penal. Parte General. Fundamentos. Tomo I (Santiago, Edit. Der).

RóDEnAs, Angeles (2015): "Normas regulativas: principios y reglas", en GonZÁLEZ LAGIER (Coord.), Conceptos básicos del Derecho (Barcelona, Edit. Marcial Pons), pp. 15-25.

Roig Torres, Margarita (2011): El concurso ideal de delitos (Valencia, Editorial Tirant Lo Blanch).

Roxin, Claus (1997): Derecho Penal. Parte General. Tomo I. Fundamentos. La estructura de la Teoría del delito (Madrid, Civitas).

Ruiz Manero, Juan (2015): "Sistema jurídico: lagunas y antinomias”, en GonZÁLEZ LaGier (Coord.), Conceptos básicos del Derecho (Barcelona, Edit. Marcial Pons), pp. 47-64.

Sanz Moran, Angel (2012): Unidad y pluralidad de delitos: La teoría del concurso en Derecho Penal (México, Edit. Ubijus).

Sanz Moran, Angel (1989): "Alternatividad de leyes penales" en: V.V.A.A., Estudios penales en memoria del Prof. Agustín Fernández Albor (Santiago de Compostela, Servicio de Publicaciones), pp. 663-676.

Sanz Moran, Ángel José (1986): El concurso de delitos: aspectos de politica legislativa (Valladolid, Universidad de Valladolid).

Silva Sanchez, Jesús María (2003): “¿Qué queda de la discusión tradicional sobre el concepto de acción?. en, del mismo, Normas y acciones en Derecho Penal (Buenos Aires, Hammurabi), pp. 41-66.

SuÁrez López, José María (2001): El concurso real de delitos (Madrid, Edersa).

Stratenwerth, Günter (2005): Derecho Penal. Parte General I. El hecho punible (Buenos Aires, Hammurabi).

VÁsquez Matos, José (1996): "Doble exposición o concurso de delitos", Revista de Derecho Puertoriqueño, No 65: pp. 205-223.

Vives Antón, Tomas Salvador (1981): La estructura de la teoría del concurso de infracciones (Valencia, Universitat de Valencia).

Welzel, Hans (1993): Derecho Penal Alemán (Santiago de Chile, Edit. Jurídica de Chile).

Van Weezel, Alex (2020): “Unidad de hecho concursal”, en Maldonado Fuentes (Coord.) Concurso de delitos. Problemas fundamentales, en prensa (texto facilitado por el autor).

Zaffaroni y Alagia, A. y Slokar, A. (2002): Derecho Penal. Parte General, 2a ed. (Buenos Aires, Edit. Ediar).

ZorzetTo, Silvia (2013): "La redundancia lingüística y las normas especiales. Algunos usos del principio Lex especialis", Doxa, Cuadernos de Filosofía del Derecho, o 36: pp. 387-415. 
